\title{
Multiple duodenal ulcer: natural history and pathophysiology
}

\author{
W M HUI AND S K LAM \\ From the Department of Medicine, University of Hong Kong, Queen Mary Hospital, Hong Kong
}

SUMmaRY It has not been established whether multiple duodenal ulcer is associated with a different natural history, pathophysiology, and therapeutic response than a single duodenal ulcer. A consecutive series of 96 patients with two or more duodenal ulcers at endoscopy, representing $9.6 \%$ of the total number of new patients with duodenal ulcer seen during the period 1980-1985, were compared with a random series of 200 patients with single duodenal ulcer seen in the middle years of this period. Multiple duodenal ulcer was associated with higher $(\mathrm{p}<0.02)$ male to female ratio, more $(\mathrm{p}<0.05)$ late onset patients (those with ulcer symptoms starting after age 30 years, more $(p<0.05)$ chronic cigarette smokers, and more frequent $(p<0.05)$ moderate to severe deformity of the duodenal bulb. More $(p<0.05)$ patients with multiple duodenal ulcer had abnormally low $\mathrm{D}_{50}$ derived from pentagastrin dose response tests, indicating that they were more sensitive to gastrin stimulation. Furthermore, their mean fasting and meal stimulated serum gastrin concentrations were significantly higher than those of patients with single ulcer $(p<0.005)$, or of controls $(\mathrm{p}<0 \cdot 05)$. Compared with single duodenal ulcer, multiple ulcer had significantly lower placebo healing rate, and required a higher dose of misoprostol (1200v800 $\mathrm{gg} / \mathrm{day})$ to achieve a similar healing efficacy at four weeks. We conclude that multiple duodenal ulcer is associated with different clinical features, pathophysiology, and possibly therapeutic response from single duodenal ulcer, and appears to represent the more aggressive side of the ulcer spectrum.

The occurrence of more than one ulcer in the duodenum, usually in the form of kissing ulcers, has long been noted by radiologists,' pathologists ${ }^{2}$ and surgeons. ${ }^{3}$ The frequency of multiple duodenal ulcer, its clinical characteristics, gastric acid and gastrin secretions, and natural history are, however, poorly understood. During the period 1980-1985, we had conducted five therapeutic trials on duodenal ulcer, in which the clinical, personal, physiological and endoscopic characteristics of all the patients were prospectively obtained. From a total of 998 new patients with duodenal ulcer seen during this period, we obtained a consecutive series of 96 patients with more than one duodenal ulcers. We have retrospectively compared these with a random series of

Address for correspondence: Prof S K Lam. MD. Department of Medicine. University of Hong Kong, Queen Mary Hospital, Hong Kong.

Received for publication 12 February 1987
200 patients with single duodenal ulcer seen during the same period, and have observed that multiple duodenal ulcer is associated with distinct clinical features, gastrin levels, natural history, and therapeutic responses. This forms the basis of this report.

\section{Methods}

PATIENTS

During the period 1980-1985, we recruited 96 consecutive patients with multiple (two or more) duodenal ulcers documented endoscopically. These patients along with others with single duodenal ulcer have been randomised into various therapeutic trials: (i) oxmetidine $v$ placebo, ${ }^{4} \mathrm{n}=120$, (ii) cimetidine $200 \mathrm{mg}$ tds $v 600 \mathrm{mg}$ nocte $v 1 \mathrm{~g} /$ day, ${ }^{,} \mathrm{n}=246$, (iii) misoprostol $300 \mu \mathrm{g}$ qid $v 200 \mu \mathrm{g}$ qid $v$ placebo, ${ }^{\circ}$ $\mathrm{n}=229$, (iv) cimetidine $1 \mathrm{~g} /$ day $v$ sucralfate $1 \mathrm{~g}$ qid, ${ }^{7}$ $\mathrm{n}=283$, and $(\mathrm{v})$ cimetidine $400 \mathrm{mg} \mathrm{tds}, 200 \mathrm{tds}$ and 
$600 \mathrm{mg}$ nocte, and $1.2 \mathrm{~g}$ nocte, $\mathrm{n}=120$. In all these clinical trials, patients with the following were excluded: concomitant medical problems, particularly renal disease, cardiovascular disease, diabetes mellitus, or chronic obstructive airways disease; pregnancy; pyloric stenosis; previous gastric operations for ulcer; associated gastric ulcer; or having received treatment for duodenal ulcer other than antacid over the past 14 days. Their clinical, personal, physiological, and endoscopic characteristics as listed in Table 1 were prospectively obtained within 72 hours before the start of treatment. The methodologies were previously reported in detail. ${ }^{+9}$

A consecutive series of 200 patients with endoscopically single duodenal ulcer recruited in the middle years of this period - that is, 1982-1983, were used as single ulcer controls.

CLINICAL AND PERSONAL CHARACTERISTICS These are described in Table 1. Further explanation is necessary for the following points. Early onset

Table 1 Patient characteristics with single and multiple duodenal ulcer prospectively obtained before commencement of treatment

\begin{tabular}{|c|c|c|c|c|}
\hline & $\begin{array}{l}\text { Individuc } \\
\text { value }\end{array}$ & $\begin{array}{l}\text { Multiple } \\
\text { duodenal ulcer } \\
n=96\end{array}$ & $\begin{array}{l}\text { Single } \\
\text { duodenal ulcer } \\
n=200\end{array}$ & $p$ \\
\hline Sex: male & $\%$ & $84 \cdot 4$ & $72 \cdot 0$ & $<0 \cdot 05$ \\
\hline Age & years & $38 \cdot 2 \pm 1 \cdot 5$ & $37 \cdot 7 \pm 1 \cdot()$ & $<0 \cdot 1$ \\
\hline Work stress & $0-3$ & $0.7 \pm 0 \cdot 1$ & $(0 \cdot 6 \pm 0 \cdot 1$ & $<0 \cdot 2$ \\
\hline Neurosis & $0-3$ & $(0.7 \pm 0 \cdot 1$ & $(0.9 \pm 0.1$ & $<0 \cdot 2$ \\
\hline \multicolumn{5}{|l|}{ Cigarette } \\
\hline non-smoker & $\%$ & $47 \cdot 9$ & $62 \cdot()$ & \multirow{3}{*}{$<0 \cdot 05$} \\
\hline$<10 /$ day & $\%$ & $17 \cdot 7$ & $14 \cdot()$ & \\
\hline$>10 /$ day & $\%$ & $34 \cdot 4$ & $24 \cdot()$ & \\
\hline Alcoholic user & $\%$ & $14 \cdot 6$ & $11 \cdot 0$ & $<0 \cdot 2$ \\
\hline Analgesic user & $\%$ & $8 \cdot 3$ & $11 \cdot 5$ & $<0 \cdot 5$ \\
\hline Family dyspepsia & $\%$ & $54 \cdot 2$ & $57 \cdot 5$ & \multirow{2}{*}{$<0 \cdot 2$} \\
\hline Strength & $0-3$ & $(0.9 \pm 0 \cdot 1$ & $1 \cdot() \pm 0 \cdot 1$ & \\
\hline Age of onset & years & $30 \cdot 7 \pm 1 \cdot 4$ & $28 \cdot 8 \pm 0 \cdot 9$ & $0 \cdot 21$ \\
\hline \multicolumn{5}{|l|}{ Early onset } \\
\hline symptoms & $\%$ & $55 \cdot 2$ & $67 \cdot 0$ & $<0 \cdot(15)$ \\
\hline Duration of & years & $7 \cdot 3 \pm 0 \cdot 1$ & $8 \cdot 9 \pm 0 \cdot 1$ & $0 \cdot 18$ \\
\hline \multicolumn{5}{|c|}{ Current symptom } \\
\hline \multicolumn{5}{|l|}{ Latest remission } \\
\hline period & months & $10 \cdot 6 \pm 2 \cdot 2$ & $7 \cdot 6 \pm 1 \cdot 1$ & 0.83 \\
\hline Pain score & $0-3$ & $1 \cdot 3 \pm 0 \cdot 1$ & $1 \cdot 2 \pm() \cdot 1$ & $<0 \cdot 2$ \\
\hline Duration of pain & hours & $2 \cdot 2 \pm 0 \cdot 8$ & $1 \cdot 3 \pm 0 \cdot 2$ & 0.18 \\
\hline Radiation to back & $\%$ & $82 \cdot 3$ & $78 \cdot 5$ & $<0 \cdot 2$ \\
\hline Nocturnal pain & $\%$ & $55 \cdot 2$ & $54 \cdot 5$ & $<0 \cdot 2$ \\
\hline Melaena & $\%$ & $65 \cdot 6$ & $69 \cdot 0$ & 0.51 \\
\hline Haematemesis & $\%$ & $15 \cdot 6$ & $20 \cdot 5$ & 0.44 \\
\hline Blood group $\mathrm{O}$ & $\%$ & $52 \cdot 8$ & $52 \cdot 5$ & \multirow{4}{*}{$<0 \cdot 1$} \\
\hline A & $\%$ & $27 \cdot 0$ & $19 \cdot()$ & \\
\hline B & $\%$ & $15 \cdot 7$ & $24 \cdot()$ & \\
\hline $\mathrm{AB}$ & $\%$ & $4 \cdot 5$ & $4 \cdot 5$ & \\
\hline
\end{tabular}

patients were defined as those having the age of onset of ulcer symptoms at age 30 years or below, and late onset as those whose symptoms started after age 30 years." Pain severity was scored as follows: nil $=0$, mild $=1$, off work or work interfering $=2$, severe, requiring immediate medical attention such as attending the casualty department $=3$. Familial dyspepsia was considered present when the patient indicated that ulcer dyspepsia, gastrointestinal bleeding, perforation, and/or gastric surgery had occurred in a first degree relative; this was scored as nil $=0$, one first degree relative $=1$, two $=2$, three or more or both parents $=3$. Stress at work was scored subjectively by patient as 0 to 3 and included work pressure and/or labour intensity of the job. Neurosis was scored according to the number of neurotic traits present with a maximum of three (insomnia, tension headache, palpitation, hand tremors, non-postural dizzy spells). Habitual cigarette smoking was scored as nil $=0,<10 /$ day $=1$, and $>10 /$ day $=2$. The majority of smokers had smoked continuously for $>10$ years, and all smokers had this habit for at least five years. Habitual alcohol consumption for at least five years was scored as nil $=0$, estimated alcohol $<50 \mathrm{~g} /$ day $=1$, $>50 \mathrm{~g} /$ day $=2$. Habitual analgesic consumption for at least one year was scored as nil $=0,1$ dose $/$ month $=1$, at least 1 dose/week $=2$; analgesics included aspirin, non-steroidal anti-inflammatory agents, and many forms of patent Chinese herbal medicine, the nature of which was mostly undefined.

\section{PHYSIOLOGICAL. CHARACTERISTICS}

Basal acid output (BAO), maximal acid output (MAO), and dose of pentagastrin required for half MAO corrected for BAO (D50C) were measured on one morning from a pentagastrin dose response test. $\mathrm{D}_{50 \mathrm{C}}$ was taken to represent the sensitivity of the parietal cells. Hypersecretor was defined as a patient having $\mathrm{MAO} / \mathrm{kg}$ total body weight above $2 \mathrm{SD}$ of the mean of normal as established previously in 100 normal Chinese subjects. Low $\mathrm{D}_{50 \mathrm{C}}$ was defined as less than $50 \mathrm{ng} / \mathrm{kg} / \mathrm{h}$, as established previously in 38 normal controls."

Serum gastrin concentrations, fasting and in response to a standard breakfast consisting of $50 \mathrm{~g}$ protein, $40 \mathrm{~g}$ carbohydrate and $40 \mathrm{~g}$ fat in the form of milk drink (60 g Sustagen in 60 milk) and Chinese style rice congee $(130 \mathrm{~g}$ minced beef in $240 \mathrm{ml}$ plain congee with $5 \mathrm{ml}$ cooking oil), were measured on another morning by radioimmunoassay. The integrated gastrin response after the standard meal of each subject was derived by computing the total area under the response curve from zero to 120 minutes. The tests were also carried out on 18 healthy volunteer controls. Based on the results of their basal and maximal acid output and serum gastrin concen- 
trations, and using the diagnostic indices of Jensen et al, ${ }^{12}$ the possibility of Zollinger-Ellison syndrome has been excluded in most of the patients. In two suspicious patients gastrin response to secretin was further determined, and were negative for gastrinoma.

\section{ENDOSCOPIC CHARACTERISTICS}

Endoscopy was carried out with a forward viewing panendoscope (Olympus GIF-P or XQ) within 72 hours before the start of treatment. The diameters and depths of the ulcer were estimated using the tips of the biopsy forceps. The endoscopic characteristics as listed in Table 2 were recorded. Ulcer site was described as anterior, posterior, floor, roof and apex (near the exit) of the duodenal bulb. The degree of surrounding inflammation was scored as gross hyperaemia, granularity, and/or oedema $=3$, moderate $=2$, mild $=1$, absent $=0$. The degree of deformity of the duodenal bulb was scored: actual narrowing of entrance or exit of the duodenal bulb by scar but still admitting the endoscope (external diameter $=$ $9 \mathrm{~mm})=3$, bilateral deformity $=2$, unilateral deformity of bulb $=1$, absent $=0$. The findings at subsequent endoscopies were compared with those observed at the initial endoscopy, and the patient was classified immediately as healed (complete disappearance of ulcer with or without residual inflammation usually in the form of hyperaemia and granularity), or unhealed (persistence of ulcer, however small).

\section{RESPONSE TO PLACEBO AND MISOPROSTOL}

\section{Placebo}

The healing response of multiple duodenal ulcer to oxmetidine placebo (one tablet at bedtime, $n=13$ ) and misoprostol placebo (two tablets half hour before breakfast, lunch and supper, and at bedtime, $\mathrm{n}=\mathrm{six}$ ) in two clinical trials were pooled together for analysis. The two trials were identical in design except for the medications, and both had endoscopic assessment at two week intervals for at least four weeks, and, if the ulcer remained unhealed, up to 12 weeks. $^{+6}$

\section{Misoprostol}

The response of multiple duodenal ulcer to different doses of a therapeutic agent was studied by analysis of the results of a randomised therapeutic trial comparing misoprostol $200 \mu \mathrm{g}$ qid, misoprostol 300 $\mu \mathrm{g}$ qid, and placebo in the healing of duodenal ulcer. In this study, antacid tablets (Gelusil, containing magnesium trisilicate $500 \mathrm{mg}$ and dried aluminium hydroxide gel $250 \mathrm{mg}$ with a neutralising capacity of $6 \mathrm{mmol} / \mathrm{l} \mathrm{HCl}$ ) was allowed for pain relief. Patients
Table 2 Physiological characteristics

\begin{tabular}{|c|c|c|c|c|}
\hline & & Multiple DU & Single DU & $p$ \\
\hline $\mathrm{BAO}$ & $\mathrm{mmol} / \mathrm{h}$ & $3 \cdot 26 \pm 0 \cdot 32$ & $3 \cdot(0 \pm 0 \cdot 18$ & 0.45 \\
\hline MAO & $\mathrm{mmol} / \mathrm{h}$ & $28 \cdot 5 \pm 1 \cdot 4$ & $27 \cdot 2 \pm 0 \cdot 72$ & 0.75 \\
\hline $\mathrm{MAO} / \mathrm{kg}$ & $\mathrm{mmol} / \mathrm{h} / \mathrm{kg}$ & $0 \cdot 50 \pm 0 \cdot(03$ & $0.49 \pm 0 \cdot 01$ & 0.83 \\
\hline Hypersecretors & $\%$ & $47 \cdot 8$ & $48 \cdot 5$ & 0.90 \\
\hline D50c & $\mathrm{ng} / \mathrm{kg} . \mathrm{h}$ & $154 \cdot() \pm 2() \cdot()$ & $123 \cdot 6 \pm 10 \cdot 0$ & 0.40 \\
\hline Low D50c & $\%$ & $42 \cdot 2$ & $29 \cdot 8$ & $<0.05$ \\
\hline Fasting gastrin & $\mathrm{pmol} / \mathrm{l}$ & $5 \cdot 1 \pm 0 \cdot 4$ & $3 \cdot 8 \pm 0 \cdot 2$ & $<0 \cdot 0002$ \\
\hline$\sum$ gastrin & $\mathrm{nmol} \cdot \mathrm{min} / \mathrm{l}$ & $10 \cdot 5 \pm 1 \cdot 0$ & $7 \cdot 3 \pm 0 \cdot 4$ & $<0 \cdot(0) 5$ \\
\hline
\end{tabular}

were endoscoped at two week intervals until the ulcer healed for at least four weeks and up to a maximum of 12 weeks. After the ulcer had healed, patients were interviewed at two month and endoscoped at four month intervals. They were to report to the ulcer clinic immediately whenever their symptoms of ulcer recurred, and endoscopy would then be carried out. The details of the trial were reported previously."

STATISTICAL ANALYSIS

Student's $t$ test, $\chi^{2}$ test for parametric data, MannWhitney test for non-parametric data, and life table analysis were used as appropriate..$^{1314}$ Values were expressed as mean $\pm S E$, and p values of less than $0 \cdot 05$ (two-sided) were considered significant.

\section{Results}

During the period 1980-1985, we recruited 998 new patients with duodenal ulcer into five therapeutic trials, of which 96 patients $(9 \cdot 6 \%)$ had multiple duodenal ulcer.

CLINICAL AND PERSONAL CHARACTERISTICS The characteristics of the 96 patients with multiple and the 200 patients with single duodenal ulcer are listed in Tables 1 and 2.

Age and sex

There were significantly $(\mathrm{p}<0 \cdot 05)$ more male patients in the multiple ulcer group $(84.4 \%, 81 / 96)$ than in the single ulcer group $(72 \cdot 0 \%, 144 / 200)$. The mean age of the multiple-ulcer $(38.2 \pm 1.5 \mathrm{yr})$ group and single ulcer $(37.7 \pm 0.95 \mathrm{yr})$ group were similar.

\section{Personal characteristics}

The mean scores for environmental stress and neurosis were practically identical in the multiple ulcer and single ulcer groups. There were significantly $(\mathrm{p}<0.05)$ more cigarette smokers in the multiple ulcer group $(52.1 \%)$ than in the single ulcer group $(38 \%)$. No significant differences were observed in their alcohol and analgesic consumptions. 
AGE OF ONSET AND GENETICS

The mean age of onset of ulcer symptoms was $30 \cdot 7 \pm 1.4$ and $28 \cdot 8 \pm 0.9$ years respectively in the multiple ulcer and single ulcer groups. When the patients were classified into early and late onset - that is, age of $<30$ or $>30 \mathrm{yr}$, significantly $(\mathrm{p}<0.05)$ more patients in the multiple ulcer group were of the late onset type when compared with the single ulcer group. A positive family history of dyspepsia occurred at similar frequencies in the two groups. Approximately half of the patients in both groups were of blood group $\mathrm{O}$, and the proportions were significantly $(p<0 \cdot 0005)$ higher than that of the general population, in which blood group $\mathrm{O}$ constituted $40 \cdot 4 \%$ (number of subjects studied $=130000)$. $^{15}$

\section{SYMPTOMS}

The mean duration of symptoms before presentation was $7 \cdot 3 \pm 0 \cdot 1$ and $8 \cdot 9 \pm 0 \cdot 1$ years respectively in the multiple ulcer and single ulcer groups, and were not statistically different. The latest period of remission, the current symptom period, and the character of the pain were not statistically different between the multiple ulcer and single ulcer groups. The duration of pain attack was longer in the multiple ulcer group $(2 \cdot 2 \pm 0 \cdot 8 \mathrm{~h})$ than in the single ulcer group $(1 \cdot 3 \pm 0 \cdot 2 \mathrm{~h})$, but the difference was not significant. The frequencies of melaena and haematemesis were also not different between the two groups.

\section{Past history of ulcer disease}

Forty seven $(49 \%)$ of the patients with multiple duodenal ulcer had their ulcers documented endoscopically for the first time in the present study. In the remaining patients, six $(12 \cdot 2 \%)$ had previous history of multiple duodenal ulcer documented endoscopically, and $43(87 \cdot 8 \%)$ were documented to have single ulcer.

\section{EN DOSCOPIC CHARACTERISTICS}

In the multiple ulcer group, $53 \cdot 1 \%$ of the index (bigger) ulcers occurred anteriorly with a kissing ulcer at the posterior wall, and $17.7 \%$ of the index ulcers were situated on the floor, with an opposite ulcer at the roof. The mean diameter of the index ulcer was significantly $(p<0 \cdot 05)$ larger in the multiple ulcer group $(7 \cdot 2 \pm 0 \cdot 3)$ than in the single ulcer group $(6 \cdot 4 \pm 0 \cdot 2)$. The mean ulcer depths were not significantly different in the two groups. Likewise the mean score of inflammation in the two groups was not different. Deformity of the duodenal bulb was significantly $(\mathrm{p}<0.005)$ more severe in the multiple ulcer than in the single ulcer group, $27 \cdot 1 \%$ and $39.5 \%$ of the patients respectively having moderate to severe deformity.
Table 3 Endoscopic characteristics

\begin{tabular}{|c|c|c|c|c|}
\hline & $\begin{array}{l}\text { Individual } \\
\text { value }\end{array}$ & Multiple IDU & Single IDU & $p$ \\
\hline Ulcer size & $\mathrm{mm}$ & $7 \cdot 2 \pm 0 \cdot 3$ & $6 \cdot 4 \pm 0 \cdot 2$ & $<0 \cdot(05$ \\
\hline Ulcer depth & $\mathrm{mm}$ & $1 \cdot 8 \pm 0 \cdot 1$ & $1 \cdot 7 \pm 0 \cdot 1$ & ()$\cdot 28$ \\
\hline \multicolumn{5}{|l|}{ Inflammation } \\
\hline Grade () & $\%$ & $11 \cdot 5$ & $11 \cdot 0$ & \multirow{4}{*}{$<0 \cdot 1$} \\
\hline 1 & $\%$ & $47 \cdot 9$ & $49 \cdot 5$ & \\
\hline 2 & $\%$ & 3()$\cdot 2$ & $36 \cdot 0$ & \\
\hline 3 & $\%$ & $10 \cdot 4$ & $3 \cdot 5$ & \\
\hline \multicolumn{5}{|l|}{ Deformity } \\
\hline Grade () & $\%$ & $34 \cdot 4$ & $46 \cdot 5$ & \multirow{4}{*}{$<0 \cdot(05$} \\
\hline 1 & $\%$ & $38 \cdot 5$ & 33.5 & \\
\hline 2 & $\%$ & $20 \cdot 8$ & $18 \cdot 0$ & \\
\hline 3 & $\%$ & $6 \cdot 3$ & 2 & \\
\hline
\end{tabular}

\section{PHYSIOLOGICAI. CHARACTERISTICS}

\section{Acid output}

The basal acid output (BAO), and the maximal acid output (MAO) of patients with multiple duodenal ulcer were respectively $3 \cdot 26 \pm 0 \cdot 32$ and $28 \cdot 2 \pm 1 \cdot 4$ $\mathrm{mmol} / \mathrm{h}$ and were similar to those of the single ulcer group (Table 3 ).

\section{Sensitivity to pentagastrin}

Although $\mathrm{D}^{2} 0_{\mathrm{c}}$ in the multiple ulcer and single ulcer groups were not statistically different, significantly $(\mathrm{p}<0 \cdot 05)$ more patients with multiple duodenal ulcer $(42 \cdot 2 \%)$ had D 50 c that was below normal than those with single duodenal ulcer $(29.8 \%)$, indicating that more patients with multiple duodenal ulcer might be hypersensitive to gastrin.

\section{Serum gastrin}

The mean fasting serum gastrin (pmol/l) in the multiple ulcer group $(5 \cdot 1 \pm 0 \cdot 4)$ was significantly higher than that of the single ulcer group $(3 \cdot 8 \pm() \cdot 2)$ $(\mathrm{p}<0 \cdot(0002)$ and that of the normal subjects $(2 \cdot 8 \pm 0 \cdot 3)$ $(\mathrm{p}<0 \cdot 005)$.

At 30,60, 120 minutes after the standard meal, the mean serum gastrin concentrations of patients with multiple ulcer were significantly higher than those of patients with single ulcer, the significant concentrations being $\mathrm{p}<0 \cdot(001,<0 \cdot 001$, and $<0 \cdot 0005$ respectively, as well as those of the normal controls, the significant concentrations being $\mathrm{p}<0 .(01,0 \cdot(05,(0)(01$ respectively (Fig. 1). The integrated two hour postprandial serum gastrin was likewise significantly higher in the multiple ulcer group (10.5 $\pm 1.0 \mathrm{nmol} /$ $\mathrm{min} / \mathrm{l})$ than in the single ulcer group $(7 \cdot 3 \pm 0.4$ $\mathrm{nmol} / \mathrm{min} / \mathrm{l})(\mathrm{p}<0 \cdot 005)$ and in the controls $(6 \cdot 5 \pm 1 \cdot()$ $\mathrm{nmol} / \mathrm{min} / \mathrm{l})(\mathrm{p}<() \cdot 05)$. The findings remained true when the male patients and controls alone were analysed (Fig. 2). 


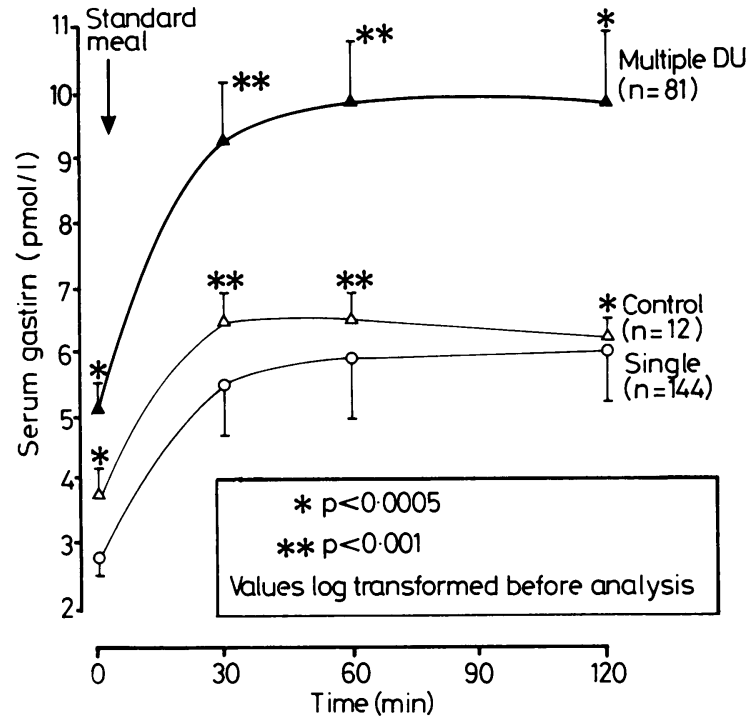

Fig. 1 Fasting and meal stimulated gastrin in multiple and single duodenal ulcer patients and controls. Multiple ulcer $\mathrm{v}$ single ulcer: fasting, $p<0 \cdot 0002,2 \mathrm{~h}$ postprandial gastrin $p<0 \cdot 005$. Multiple ulcer $v$ control: fasting, $p<0 \cdot 005,2 \mathrm{~h}$ postprandial gastrin $p<0.05$.

RESPONSE TO PLACEBO AND MISOPROSTOL In the misoprostol study, a total of 229 patients including 21 with multiple and 208 with single duodenal ulcer were recruited into the study. Eight patients in the single ulcer and none in the multiple ulcer group dropped out.

\section{Response to placebo}

A total of 19 patients with multiple duodenal ulcer and 112 patients with single ulcer received placebo. They were patients who participated in two similarly designed, 12 week studies on oxmetidine ${ }^{4}$ and misoprostol," as described earlier.

The endoscopic healing rate at four weeks was significantly $(\mathrm{p}<0 \cdot 05)$ lower in the multiple ulcer $(5 \%)$ group than the single ulcer group $(25 \%)$, but no significant differences in the healing rates were found at eight and 12 weeks between the multiple ulcer (42\%, 47\% respectively) and single ulcer groups ( $40 \%, 55 \%$ respectively), and in the overall comparison of the two ulcer groups over the 12 weeks of the study $(p=0 \cdot 19$, life table analysis) (Fig. 3).

\section{Response to misoprostol}

The healing rates of the multiple ulcer and single ulcer groups were shown in Figure 4. Patients with multiple duodenal ulcer healed significantly slower than those with single duodenal ulcer when treated with misoprostol $200 \mu \mathrm{g}$ qid $(\mathrm{p}<0.05$ by life table

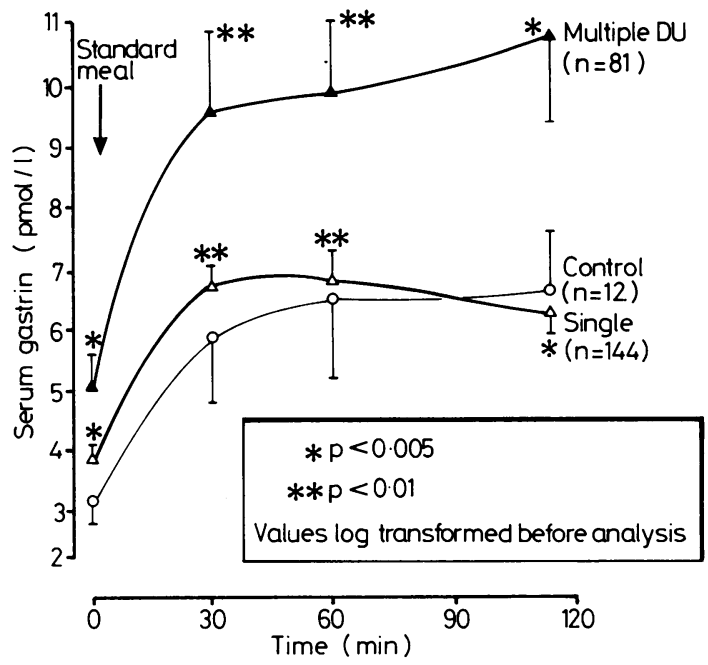

Fig. 2 Fasting and meal stimulated gastrin in male patients with multiple and single duodenal ulcer and controls. Multiple ulcer v single ulcer: fasting, $p<0.005,2 \mathrm{~h}$ postprandial gastrin $p<0 \cdot 05$. Multiple ulcer $v$ single ulcer: fasting, $p<0 \cdot 05,2$ postprandial gastrin $p<0.05$.

analysis), but this disadvantage disappeared $(p>0 \cdot 5)$ when the patients were treated with the higher dose of misoprostol, $300 \mu \mathrm{g}$ qid. At the end of four weeks, significantly $(\mathrm{p}<0.05)$ more patients with multiple duodenal ulcer on misoprostol $300 \mu \mathrm{g}$ qid $(87.5 \%)$ had their ulcers healed than those on misoprostol 200 $\mu \mathrm{g}$ qid (14\%) (Fig. 4). Irrespective of the treatment received, patients with multiple duodenal ulcer consumed significantly more antacids than those with single duodenal ulcer all through the 12 week period of the study. For example, the mean number of

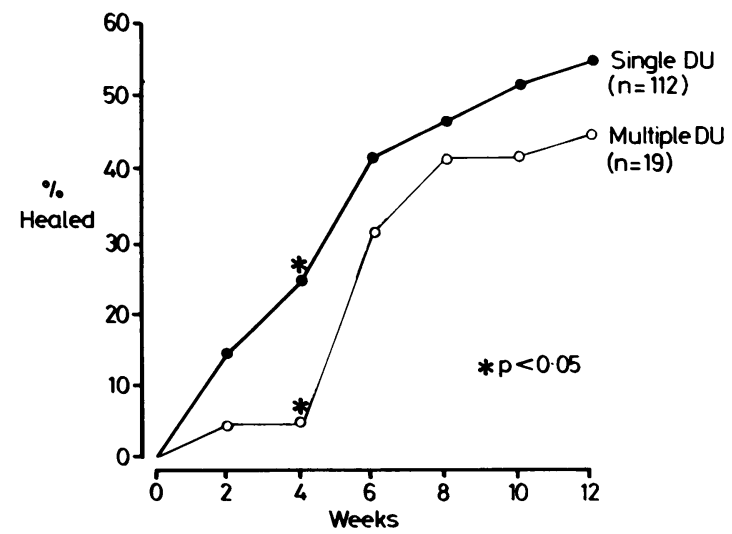

Fig. 3 Healing rates of multiple and single duodenal ulcer treated with placebo. $p<0.05$ at wk 4; life table analysis of multiple ulcer $v$ single ulcer over $12 \mathrm{wk}$ : p not significant. 

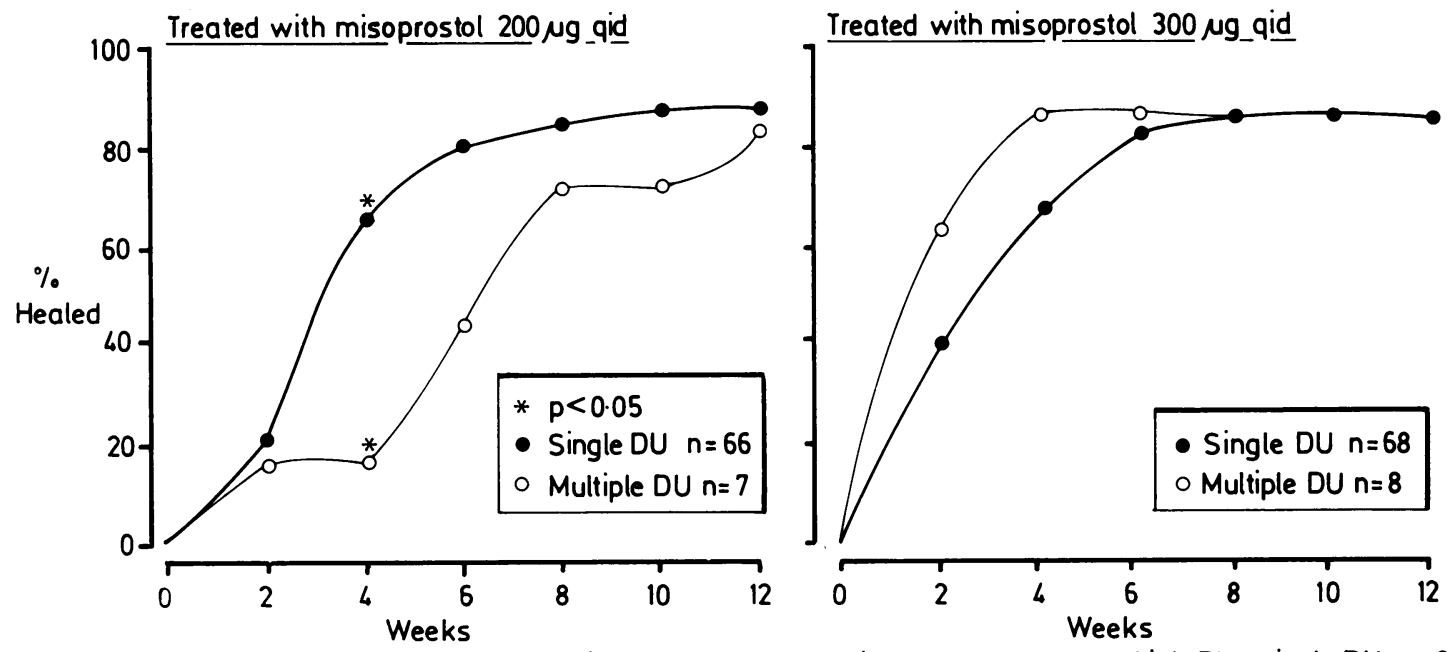

Misoprostol 200 g:multiple DU v single DU p 0.05 Misoprostol $300 \mu \mathrm{g}$ : multiple DU v single DU p 0.5

Fig. 4 Healing rates of multiple and single duodenal ulcer treated with misoprostol $200 \mu \mathrm{g}$ qid and $300 \mu \mathrm{g}$ qid. Life table analysis of multiple ulcer $v$ single ulcer: treated with misoprostol $200 \mu \mathrm{g}$ qid $p<0 \cdot 05$, treated with $300 \mu \mathrm{g}$ qid p not significant.

antacids consumed at the end of four weeks by patients taking misoprostol $300 \mu \mathrm{g}$ qid, $200 \mu \mathrm{g}$ qid and placebo were $1 \cdot 1,2 \cdot 1$, and $2 \cdot 0$ respectively in the single ulcer groups, and $3 \cdot 8,5 \cdot 5$, and $8 \cdot 2$ respectively in the multiple ulcer group. It should be noted that misoprostol $200 \mu \mathrm{g}$ qid is the recommended dose for the treatment of duodenal ulcer as established by mutiple therapeutic trials. ${ }^{16}$

FOLLOW UP

Sixty three of the patients with mutiple duodenal ulcer completed a follow up period of two years after initial healing of their ulcers by various therapeutic agents including $\mathrm{H}_{2}$-receptor antagonists, misoprostol, sucralfate, and placebo. Forty eight $(76 \cdot 2 \%)$ had relapsed with a single ulcer, seven $(11 \cdot 1 \%)$ had relapsed with multiple ulcers, and eight $(12.7 \%)$ had no relapse. Of the 200 patients with single duodenal ulcer, 134 had completed a follow up period of two years, and $107(79 \cdot 8 \%)$ had relapsed; none of the recurrent ulcers were multiple. Patients with multiple duodenal ulcer did not have an increased relapse rate $\left(\chi^{2}=1 \cdot 16, p>0 \cdot 05\right)$.

\section{Discussion}

Several differences between patients with multiple duodenal ulcer and those with single duodenal ulcer emerge from this prospective study comparing their clinical and personal characteristics, gastric physiological measurements, natural history, and therapeutic response.
Patients with multiple duodenal ulcer have significantly more male preponderance, more cigarette smokers, and more late onset disease - that is, patients whose symptoms start after the age of 30 years. Duodenal ulcer has been shown to heal more spontaneously in men than in women. ${ }^{17.14}$ Cigarette smoking delays ulcer healing not only in patients treated with placebos but also in those treated with potent acid reducing agents such as $\mathrm{H}_{2}$-receptor antagonists, as has recently been reviewed. "I" Compared with early onset disease, late onset duodenal ulceration is known to be more often associated with virulent ulcers such as postbulbar ulcers and giant duodenal ulcers, and to be more often associated with perforation and pyloric stenosis." These observations suggest that multiple duodenal ulcer may be a more severe disease and may run a higher risk of complications than single duodenal ulcer.

This concept is further supported by the findings in this study that multiple duodenal ulcer is significantly bigger, associated with greater deformity of the duodenal bulb, and is significantly more difficult to heal than single duodenal ulcer, as evident by its lower placebo healing rate at four weeks, and the requirement of a higher dose of misoprostol than recommended. As the number of patients involved in the mutiple duodenal ulcer group was small, however, further studies are required to confirm their apparent resistance to heal.

The pathophysiological basis for the aggressive nature of multiple duodenal ulcer is not clear. Both basal and maximal acid output are significantly 
higher than normal, although these are not significantly different from those of patients with single duodenal ulcer. The fasting and meal stimulated serum gastrin concentrations of patients with multiple duodenal ulcer are significantly higher than those of the single ulcer patients, however, as well as normal controls, and significantly more of them are abnormally sensitive to gastrin. These findings suggest that gastrin cell hyperfunction and gastrin hypersensitivity may be two basic physiological abnormalities in these individuals, and may be responsible for the multiplicity and aggressiveness of their ulcers. It is not known from this study whether these patients have antral G cell hyperplasia, a rare condition associated with gross hypergastrinaemia and acid hypersecretion. ${ }^{21}$ Gastrin cell hyperfunction in the form of postprandial but not fasting hypergastrinaemia has been described in patients with normal acid secretory capacity,"= and may occur in about one third of patients with duodenal ulcer. ${ }^{y}$ It is tempting to suggest that duodenal ulcer with postprandial hypergastrinaemia alone, which occurs commonly in about one third of the patients, multiple duodenal ulcer, which occurs in about $10 \%$ of patients with duodenal ulcer as shown in this study, and duodenal ulcer associated with antral $G$ cell hyperplasia, which occurs rarely, fall in the same spectrum of duodenal ulcer having various degrees of gasirin cell abnormalities. Whether postprandial hypergastrinaemia has resulted in hypersecretion of meal stimulated acid output is not known from this study, although this relationship has been shown in a previous report. ${ }^{33}$

Treatment of duodenal ulcer associated with postprandial hypergastrinaemia does not differ from that of ordinary patients with duodenal ulcer, whereas treatment of patients with antral $G$ cell hyperplasia may require surgical resection of the antrum. ${ }^{21}{ }^{24}$ It is interesting that treatment of patients with multiple duodenal ulcer requires a higher dose of misoprostol than is generally recommended. Misoprostol is a synthetic prostaglandin $E_{1}$ derivative with potent antisecretory and cytoprotective properties, ${ }^{5.52}$ with a unique advantage of being able to nullify the adverse effects of cigarette smoking on duodenal ulcer healing," a habit which occurs more commonly in patients with multiple than with single duodenal ulcer as observed in this study.

Our follow up study suggests that after the initial healing of the ulcers by various therapeutic agents, the majority of the patients with multiple duodenal ulcer tended to relapse with single ulcer rather than multiple ulcers, and only about $10 \%$ relapse with multiple ulcers. It is possible that the close follow up of our patients with two monthly visits and four monthly endoscopies may have led to earlier detec- tion of relapse, at a time when the ulcer was still single. It is also possible that the natural history of these patients is such that the ulcer may reappear as single or multiple ulcer depending on certain underlying, unknown factors. It is not known from this study whether the fasting and postprandial hypergastrinaemia, and the apparently slower response to treatment persist in these patients with relapse.

We conclude that multiple duodenal ulcer is associated with different pathophysiology, clinical features, natural history, and possibly, therapeutic responses from single duodenal ulcer.

This study was supported by the Peptic Ulcer Research Fund (311/041/0372) and University Grants $(311 / 030 / 8009 / 31, \quad 311 / 030 / 8010 / 12,335 / 041 / 0006$, $311 / 030 / 8010 / 69$ ) of the University of Hong Kong.

The authors are grateful to $\mathrm{M}$ Chong, $\mathrm{B} \mathrm{Ng}$, J Wong, B Chik, and A Cheng for nursing assistance, and to GH Joe and P Yip for technical assistance.

\section{References}

1 Clark CA, Edwards JW, Haddock DRW, Howel Evans AW, McConnell RB, Sheppard PM. ABO blood groups and secretor character in duodenal ulcer. Br Med J 1956; 2: 125 .

2 Cooke L, Hutton CF. Post-bulbar duodenal ulcer. Lancet 1958; i: 754.

3 Evans RW. In: C Wells, J Kyle, eds. Peptic ulceration. Edinburgh and London: Livingstone, 1960): 37-54.

4 Lam SK, Lai CL, Louis Lee NW, Fok KH, Matthew Ng MT, Siu KF. Factors influencing healing of duodenal ulcer. Dig Dis Sci 1985; 30: 45-51.

5 Lam SK, Lai CL, M Ng, Fok KH, Hui WM. Duodenal ulcer healing by separate reduction of postprandial and nocturnal acid secretions have different pathophysiology. Gut 1985; 26: 1038-44.

6 Lam SK, Lau WY, Choi TK, et al. Prostaglandin E1 (misoprostol) overcomes the adverse effect of chronic cigarette smoking on duodenal ulcer healing. Dig Dis Sci 1986; 31: suppl: 1S-7S.

7 Lam SK, Hui WM, Lau WY, et al. Sucralfate overcomes adverse effect of cigarette smoking on duodenal ulcer healing and prolongs subsequent remission. Gastroenterology 1987; 92: 1193-1201.

8 Lam SK, Koo J. Accurate prediction of duodenal-ulcer healing rate by discriminant analysis. Gastroenterology 1985; 85: 403-12.

9 Lam SK, Ong GB. Relationship of postprandial serum gastrin response to sex, body weight, blood group status, familial dyspepsia, duration, and age of onset of ulcer symptoms in duodenal ulcer. Gut 1980; 26: 528-32.

10 Lam SK, Ong GB. Duodenal ulcers: early and late onset. Gut 1976; 17: 169-7.

11 Lam SK, Koo J. Gastrin sensitivity in duodenal ulcer. Gut 1985; 26: 485-90.

12 Jensen RT, Gardner JD, Raufman JP, et al. Zollinger- 
Ellison: current concepts and management. Ann Intern Med 1983; 98: 59-75.

13 Fleiss JL. Statistical methods for rates and proportions. New York: Wiley, 1973.

14 Snedecor GW, Cochran WG. Statistical methods. Ames, Iowa: Iowa State University Press, 1967.

15 Annual Statistics of Red Cross Blood Transfusion Service, Hong Kong, 1984.

16 Lam SK. Prostaglandins in the treatment of gastric and duodenal ulcer. J Gastroenterol Hepatol 1986; 1: 471-81.

17 Frederiksen H-JB, Matzen P, Madsen P, et al. Spontaneous healing of duodenal ulcers. Scand $J$ Gastroenterol 1984; 19: 417-21.

18 Peden NR, Boyd EJS, Wormsley KG. Woman and duodenal ulcer. Br Med J 1981; 282: 866 .

19 Lam SK, Lam KC, Lai CL, et al. Treatment of duodenal ulcer with antacid and sulpiride. A double-blind controlled study. Gastroenterology 1979; 76: 316-22.

20) Lam SK. The stomach. In: Gitnick G, ed. Current gastroenterology. New York: Year Book Medical Publishers, 1986: 33-62.
21 Taylor IL, Calam J, Rotter JL, et al. Family studies of hypergastrinemic, hyperpepsinogenemic I duodenal ulcer. Ann Intern Med 1981; 95: 421-5.

22 Byrnes DJ, Lam SK, Sircus W. The relation between functioning parietal cell and gastrin cell masses in two groups of duodenal ulcer patients. Clin Sci Mol Med 1976; 50: 375-83.

23 Lam SK, Isenberg JI, Grossman MI, Lane WH, Walsh $\mathrm{JH}$. Gastric acid secretion is abnormally sensitive to endogenous gastrin released after peptone test meals in duodenal ulcer patients. J Clin Invest 1980; 65: 555-62.

24 Lamers CBH, Roland CM, Joosten HJM, et al. Hypergastrinaemia of antral origin in duodenal ulcer. Dig Dis Sci 1978; 23: 998-1002.

25 Steiner JA. Misoprostol clinical pharmacology. Establishment of activity in man. Dig Dis Sci 1985; 30: suppl: $136 \mathrm{~S}-141 \mathrm{~S}$.

26 Liss RH, Letourneau RJ, Schepis JP. Evaluation of cytoprotection against ethanol-induced injury in gastric mucosa pretreated with misoprostol, cimetidine or placebo. Dig Dis Sci 1986; 31: suppl: 1S-7S. 